\title{
SXSW Eco Backdrops
}

\section{KORY BIEG}

The University of Texas at Austin

This project was for the design of stage backdrops for the 2015 SXSW Eco Conference held in Austin, TX. The backdrops provided a consistent branding for the event that spanned three days and took place on seven stages. Due to the quick turnover between events held at the Austin Convention Center, the backdrop had to be fully assembled and disassembled using union labor and within two hours. To facilitate handling and transport, the backdrop was designed as $4^{\prime}-0^{\prime \prime} \times 8^{\prime}-0^{\prime \prime}$ modules. More or less modules could be used depending on the size of the stage. Each module surface could be removed from the backing frame and folded like an accordion to fit in a standard moving truck. Additionally, the budget was extremely low, averaging \$100 per panel. To limit the cost, we used chipboard for the surface, except for the keynote stage, where we used paper-backed maple veneer.

The design began with a study of wrinkles and specifically the work of Burne Hogarth - illustrator of early Tarzan comics. His approach to drawing the clothed body was unique at the time, and he cataloged every wrinkle type according to force and form. To recreate these effects, we used a dynamic cloth simulation program, adjusting force, material and object collisions to achieve a range of folded pleats. The final surface is reminiscent of a red theater backdrop, but unique in its fabrication, detail and tectonic articulation. 

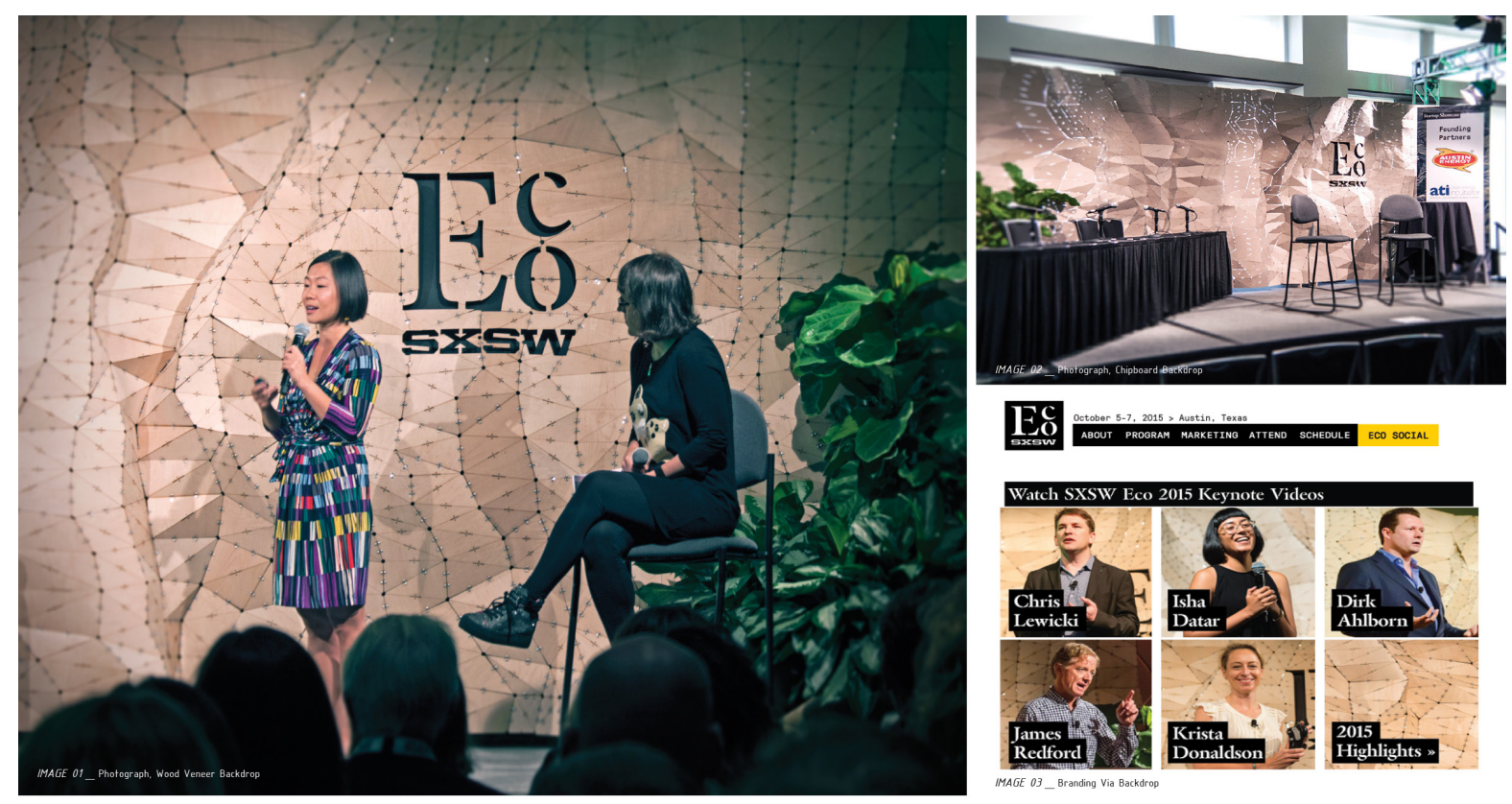

EC.

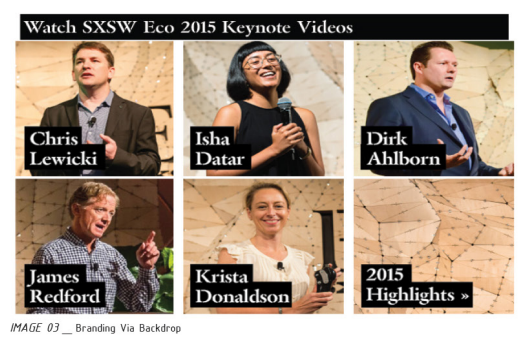

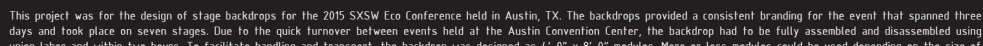

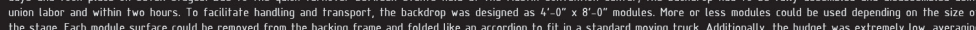

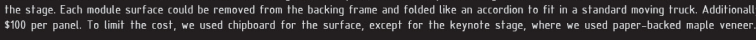

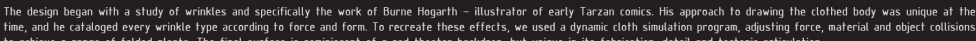

\section{SXSW ECO Backdrops}
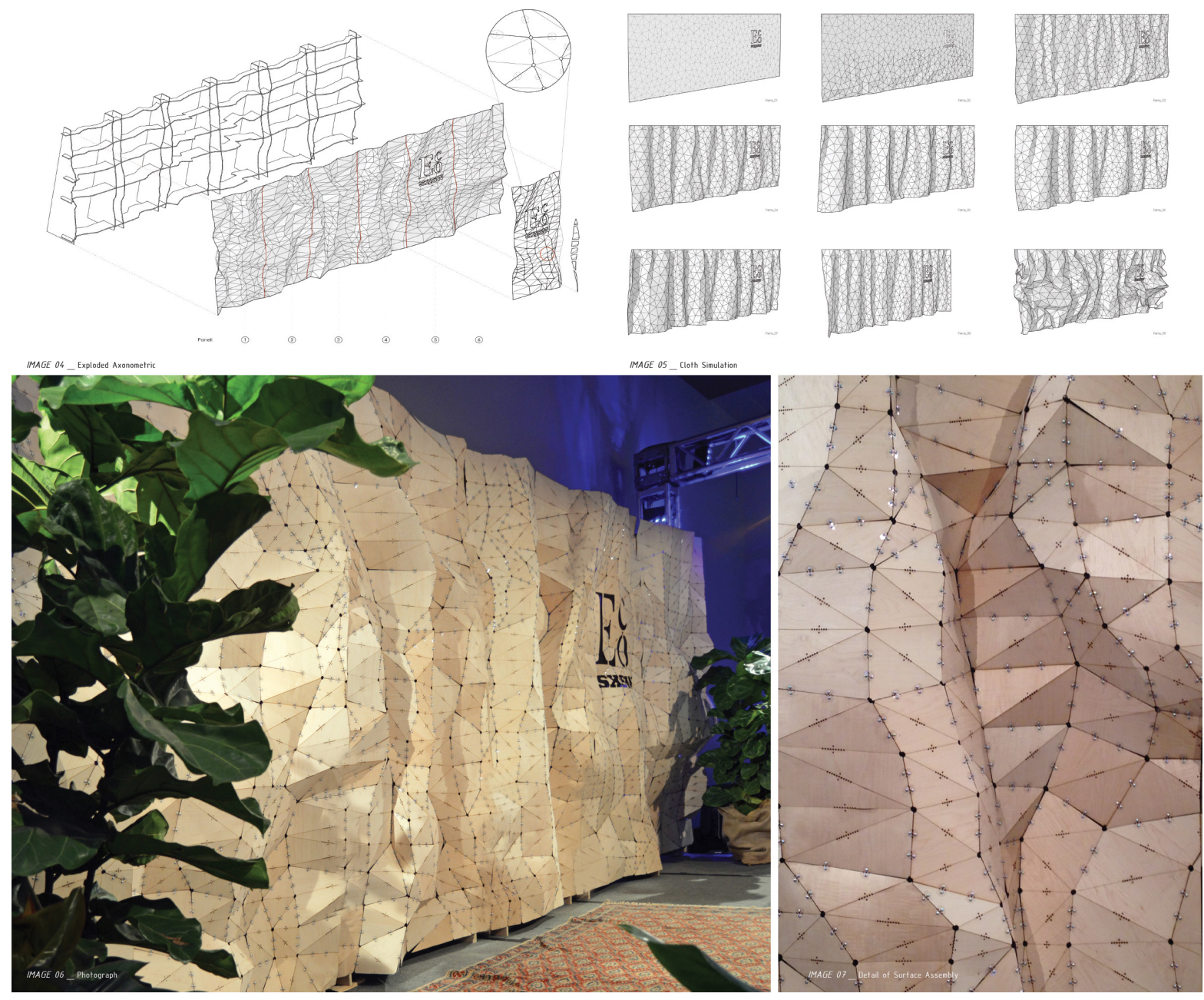